\title{
O TRAÇADO URBANO DA CIDADE DE SÃO MIGUEL DO OESTE-SC: ASPECTOS DO PATRIMÔNIO HISTÓRICO E CULTURAL
}

\author{
Larissa Emanuelle Dalpasquale Zalamena ${ }^{1}$ \\ Paulo Ricardo Bavaresco ${ }^{2}$
}

\begin{abstract}
RESUMO: O presente artigo é resultado da pesquisa que objetivou analisar o traçado urbano de cidade de São Miguel do Oeste - SC. Buscamos demonstrar como o traçado urbano de uma cidade faz parte do Patrimônio Histórico e Cultural do município. Ao mesmo tempo analisamos os motivos da não preservação do traçado urbano na cidade do referido município quando da criação de novos loteamentos, pergunta central da proposta de estudo. A pesquisa contou, primeiramente, com um diálogo sobre patrimônio histórico e a cidade sobre o viés do capital. Na pesquisa de campo estudamos os loteamentos que surgiram nos últimos anos. Foi possível notar que o desenho urbano, a partir do surgimento dos novos loteamentos, alterou o padrão existente, quanto a largura das ruas e o tamanho dos lotes em comercialização. $\mathrm{O}$ capital, ao mesmo tempo em que interfere no espaço urbano, fragiliza o patrimônio histórico da cidade, no caso de São Miguel do Oeste-SC o seu traçado urbano.
\end{abstract}

Palavras-chave: Patrimônio histórico; História; Cidade; Traçado urbano.

THE URBAN OUTLINE OF THE CITY OF SÃO MIGUEL DO OESTE-SC: ASPECTS OF HISTORICAL AND CULTURAL HERITAGE

\begin{abstract}
This article is the result of research that aimed to analyze the urban layout of the city of São Miguel do Oeste - SC. We seek to demonstrate how the urban layout of a city is part of the Municipality's Historical and Cultural Heritage. At the same time, we analyzed the reasons for not preserving the urban layout in the city of that municipality when creating new subdivisions, a central question of the study proposal. The research had, first, a dialogue about historical heritage and the city about the capital's bias. In the field research, we studied the subdivisions that emerged in recent years. It was possible to notice that the urban design, from the appearance of the new subdivisions, changed the existing pattern, as for the width of the streets and the size of the lots being sold. The capital, while interfering in the urban space, weakens the city's historical heritage, in the case of São Miguel do Oeste-SC its urban layout.
\end{abstract}

Keywords: Historical heritage; History; City; Urban layout.

\section{INTRODUÇAO}

\footnotetext{
${ }^{1}$ Acadêmica do Curso de Arquitetura e Urbanismo da Universidade do Oeste de Santa Catarina UNOESC, Campus de São Miguel do Oeste. E-mail: lariedalpasquale@gmail.com

2 Doutor em Ciências Sociais, professor e pesquisador Universidade do Oeste de Santa Catarina UNOESC E-mail: .paulo.bavaresco@unoesc.edu.br
} 
Patrimônio é uma expressão antiga ligada à ideias de estruturas familiares, econômicas e jurídicas. No entanto, desde sua origem, o significado por trás dessa expressão vem se modificando e sendo agregada a novos conceitos (CHOAY, 2006). O patrimônio não é restrito apenas a imóveis, bens materiais ou valores monetários, mas em seu significado atual, abrange imóveis particulares ou públicos, trechos urbanos, e até mesmo objetos com valores apenas sentimentais, podendo ser individual ou coletivo (FUNARI; PELEGRINI, 2006).

De acordo com Choay (2006), o termo refere-se, nos dias atuais, a um bem designado ao aproveitamento de uma comunidade, sendo constituído pela acumulação de uma variedade de objetos e heranças que são ligadas por sua importância, tanto no passado como no presente.

Até pouco tempo, as vias urbanas eram vistas apenas como uma continuidade da cidade, passiveis de mudanças e adaptações, assim como deu-se em Paris, quando Haussmann, em prol da harmonia, higiene e trânsito, destruiu parcelas inteiras da malha urbana parisiense. Com o intuito de modernização das cidades, as ruelas escuras deram lugar a largas avenidas, e porções demolidas, à moradias decentes ao homem, permitindo a entrada de luz e ventilação natural. As antigas ruas e construções, eram vistas apenas como obstáculos à limpeza e saúde, situação que de certa forma autorizou a transformação completa da malha urbana das antigas cidades, configuradas apenas como uma continuidade do conjunto urbanoe não como um monumento. (CHOAY, 2006)

Segundo Choay (2006), nota-se que nesse período, 1853, a cidade e as vias urbanas em si não eram vistas como um patrimônio especifico, capazes de serem conservadas como um monumento histórico. No entanto o autor deixa claro, que foi na própria época de Haussmann ${ }^{3}$ que começa a surgir a noção de patrimônio histórico, juntamente com projetos de conservação.

A partir dessa nova abrangência, percebe-se a incorporação de outras particularidades à ideia de patrimônio, onde se incluem a malha viária e as próprias vias

\footnotetext{
${ }^{3}$ George-Eugène, barão de Haussmann, nomeado prefeito de Paris, foi um dos maiores urbanizadores do Século XIX. 
de circulação ${ }^{4}$ conhecidas atualmente. As redes de infraestrutura são muito antigas, e acompanharam a evolução das cidades, sendo a rede viária ${ }^{5}$ a primeira a surgir, herança deixada primeiramente, assim como o patrimônio, pelos povos romanos. Constituíam-se inicialmente por perfis de calçamento utilizadas principalmente para uso militar, passagem de carroças e pessoas. Entretanto, a maior evolução ocorreu com o surgimento do automóvel (MASCARÓ; YOSHINAGA. 2005).

O reconhecimento da cidade e da malha urbana como um objeto material ocorreu a partir da modificação do espaço urbano no período da Revolução Industrial no Séc XVIII, onde a cidade antiga passou a ser estudada para o surgimento de novas escalas urbanas. A partir desse momento, arquitetos e engenheiros entram em cena para entendê-la, surgindo então o urbanismo (CHOAY, 2006).

De acordo com RuskinapudChoay (2006), a malha urbana é o conteúdo da cidade, o que faz dela um patrimônio intocável e que deve ser inteiramente protegido. Atualmente, o sistema viário é percebido como um dos elementos mais nítidos na forma de uma cidade, que dispõe a ordem dos edifícios e quarteirões e tem a função de ligar os diversos espaços e partes de uma localidade. O traçado caracteriza o plano, e está relacionado com o crescimento da cidade de forma hierárquica, em função da importância do deslocamento e do percurso de pessoas e objetos. (LAMAS, 2011)

Os moradores de cada localidade precisam ter uma ligação com a cidade, sentir-se parte dela e a partir do conhecimento de sua história, valorizar o lugar em que habitam, não vendo-a meramente como local de moradia, trabalho e lazer. Cada imóvel e traçado urbano preservados revelam as características das pessoas, famílias que ali iniciaram, quais eram seus conhecimentos, costumes, hábitos e materiais disponíveis na época, assim como os problemas enfrentados e as soluções encontradas por eles. Esse conhecimento auxilia na formação da identidade cultural do povo, como na criação de programas e políticas públicas que respeitem a história das pessoas que construíram a cidade para os cidadãos e para viverem, não visando apenas o capital. Com base nisso, pretende-se relevar a história do traçado urbano de São Miguel do Oeste, e como ele

\footnotetext{
${ }^{4}$ Malha Viária - vias do Município, classificadas e hierarquizadas segundo critério funcional, observados os padrões urbanísticos do município. Vias de circulação - vias abertas a circulação de acordo com sua utilização.

${ }^{5}$ Arede viária - mapa com as atuais rotas rodoviárias, ferroviárias, etc. 
representa um Patrimônio Histórico e Cultural da cidade, a fim de ressaltar sua importância.

Em um primeiro momento realizou-se uma pesquisa bibliográfica com diversos autores, para contextualizar inicialmente os impactos do capital na reestruturação das cidades e posteriormente uma pesquisa bibliográfica da história de São Miguel do Oeste, a fim de realizar um comparativo com a situação atual.

\section{A CIDADE E O CAPITAL}

Segundo Lefebvre (1999), o capitalismo se fez mais presente a partir de 1845 , com a Revolução Industrial, um ambiente fabril, a formação de uma classe operária e uma nova realidade que se multiplicava com rapidez. A sociedade nova que se origina a partir desse período, possui traços característicos e de fácil percepção, onde o poder econômico torna-se o centro dos interesses sociais. Homens transformam-se em máquinas, realizando atividades repetidamente e por longos períodos, vilarejos surgem em torno das fábricas e aos poucos, toda a cidade fica refém dessa nova prática, que visa exclusivamente o lucro.

A relação dos objetos ou serviços com o capital implica no seu valor de uso e valor de troca, afirma Lefebvre (1999, p. 135) que "O valor de uso corresponde à necessidade, à expectativa, à desejabilidade. $\mathrm{O}$ valor de troca corresponde à relação dessa coisa com as outras coisas, com todos os objetos e com todas as coisas [...]." Esse conhecido "mundo da mercadoria" se amplia, de modo que abrange o mercado mundial, onde tudo se compra e tudo se vende e o principal objetivo do capitalista é gerar dinheiro e obter lucro, tornando-o um ciclo vicioso (LEFEBVRE, 1999).

Neste contexto, de acordo com Lefebvre (1999), as necessidades sociais ficam a cargo do Estado, que são tratadas em função dos interesses de uma pequena parcela da sociedade privilegiada, transitando as decisões entre a propriedade privada, a da terra e a do capital. A cidade passa a fazer parte dessas circunstâncias históricas ligadas ao capitalismo, sendo resultado dos interesses de uma classe e da acumulação do capital. $\mathrm{O}$ sistema contratual (jurídico), que o "Estado mantém e aperfeiçoa enquanto poder (político) repousa na propriedade privada, a da terra (propriedade imobiliária) e a do dinheiro (propriedade mobiliária)" (LEFEBVRE, 1999, p. 138). 
Com o tempo, as condições do capitalismo e as necessidades dessa parcela da população privilegiada são aceitas como naturais e culturais, dando espaço para que se promovam ainda mais. A cidade abriga e faz parte das mais diversas faces do capitalismo, tendendo à sua autodestruição, quando esse começa a se destacar nas decisões sociais e urbanas. A cidade conforma-se como um palco para os desejos e ações da classe mais imponente e aos poucos começa a ser prejudicada pelos interesses desses, a ponto de perder sua identidade histórica para fornecer mais dinheiro à uma pequena parcela de pessoas (LEFEBVRE, 1999).

De acordo com Carlos (2004), no mercado imobiliário o solo urbano torna-se mercadoria, agregando uma sentença acumulativa por meio da venda, troca e aluguel, visando a reprodução do capital. Isso significa, segundo a autora, que há diversos interesses envolvidos no uso e concepção dos espaços. É em meio a este jogo de interesse que são, por diversas vezes, deixadas de lado questões importantes como o traçado urbano regular, visando somente o lucro e desconsiderando as características e história local.

A cidade e a sociedade que ela abriga se confundem em diversas ocasiões, pois a primeira, recebe o poder capitalista conhecido como Estado e, ele por sua vez a administra. É na cidade que todas as relações comerciais e sociais acontecem. É ela que por muitas vezes sacrifica, em prol do capitalismo e do progresso, o meio ambiente e suas riquezas naturais, criando um aglomerado de subprodutos sociais; e em outras é sacrificada, também visando o lucro, tendo sua história e evolução destruídas por novos contextos capitalistas (LEFEBVRE, 1999).

Para Carlos (2001), o sistema de produção capitalista produz um espaço, assim como todo modo de elaboração, no entanto, esse só ocorrerá se permitir a valorização do capital, tendo sempre um lado estratégico e político de grande importância e influência. E essa relação estende-se também à formação dos espaços em uma cidade.

De acordo com Lefebvre (1999), a civilização foi marcada pela propriedade mobiliaria da terra, pelo dinheiro e capital que ela fornece. Desde antigamente o homem enriquece comprando terras, utilizando-a e construindo nela. A sociedade incorpora a terra ao mercado, fazendo dela um "objeto" comercializável, com um valor de troca e não um valor de uso. Os terrenos disponíveis para construção da cidade, seus preços e especulação imobiliária criam um novo cenário, onde a terra passa a ser vendida por 
parcelas, e isso acarreta na transformação das cidades, a forma dos edifícios passa a ser resultado dos loteamentos e da compra da terra fracionada.

A cidade é portanto, de acordo com Carlos (2001), uma atividade materializada, surgindo da relação do construído com o não construído, das articulações entre um e outro e das movimentações dentro dela, tanto de pessoas como de mercadorias. Sua paisagem é composta por diversos momentos históricos diferentes, produzidos pelas relações entre o novo e o velho.

No princípio, a palavra patrimônio era ligada à ideia de estruturas familiares, termo que vem, com o tempo, se modificando e tendo novos conceitos agregados. Hoje sabe-se que patrimônio não está limitado apenas a imóveis e bens materiais, abrangendo também trechos urbanos e até mesmo objetos com valores apenas sentimentais (FUNARI; PELEGRINI, 2006).De acordo com o Instituto do Patrimônio Histórico e Artístico Nacional - IPHAN (2014), diversas são as cidades brasileiras com espaços públicos tombados, inclusive seu traçado urbano, muitos mantidos desde a época colonial, que engloba diversos outros patrimônios em sua extensão, tendo uma importante parte da história preservada, para que todas as gerações possam ter acesso e vivenciar peculiaridades de outras épocas.

Choay (2006, apud RUSKIN, 1861), declara que a malha urbana é o conteúdo da cidade, fazendo dela um patrimônio intocável, que deve ser inteiramente protegida. Para Lamas (2011), o sistema viário é um dos elementos mais evidentes na forma de uma cidade, já que dispõe a ordem dos edifícios e quarteirões, com a função de ligar os espaços entre um local e outro, assim como na compreensão das intenções de quem a projetou. É o traçado que define o plano, ligado diretamente ao sentido de permanência, já que não é totalmente modificável.

Há pouco tempo percebeu-se a importância do traçado urbano como patrimônio histórico, e suas qualidades para a história de cada local, isso porque, de acordo com Somekh (201-), organizadora do livro "Preservando o Patrimônio Histórico: um manual para gestores municipais", o valor figurativo atribuído a alguns bens transforma-se em valor econômico quando expande a imagem da cidade, atraindo assim novos olhares e negócios. Portanto, a preservação de determinados trechos está aliada à diversos melhoramentos, promovendo uma articulação urbana, aumentando seus lucros e rendimentos. 
No entanto, a mesma questão faz o traçado urbano ser deixado de fora na concepção de novos loteamentos e partes de cidades, quando o poder econômico e aquisitivo fica na frente da história local e popular, dando lugar a interesses comerciais de compra e venda. Isso vem tornando-se um problema nos dias atuais, onde percebe-se ruas cada vez mais estreitas,sem um traçado organizado e sem seguir as funções pelas quais foram pensadas, visando somente o aumento dos lotes e o consequente lucro financeiro.

Preservar um patrimônio é manter viva as lembranças de uma cidade, é conceder uma identidade única ao local, a fim de que planejem seu futuro sem desconsiderar o passado. Para Choay (2006, apud RUSKIN, 1861), a malha urbana apresenta um papel memorial de monumento, que fixa seus habitantes e relações no espaço e no tempo, possuindo uma perspectiva histórica que deve ser mantida para a garantia de uma identidade pessoal, local, nacional e humana.

Choay (2006) cita o relatório apresentado por Guizot, Ministro do Interior, ao rei, em 21 de outubro de 1830, para a criação do cargo de inspetor geral dos monumentos históricos na França, ressaltando a importância dos mesmos:

\footnotetext{
"Vossa Alteza, os monumentos históricos que cobrem o solo da França causam admiração e inveja à Europa erudita. Tão numerosos quanto os dos países vizinhos e mais variados, eles não pertencem apenas a uma determinada época da História, mas formam uma série completa e sem lacunas, desde os druidas até os nossos dias, não há uma época memorável da arte e civilização que não tenha deixado em nossa terra monumentos que a representem e expliquem. (...) A França não pode ficar indiferente a essa parte notável de sua glória (GUIZOT, 1830apud CHOAY, 2006, p. 259).
}

Esse contexto configura-se como um desafio da modernização, onde, atualmente, diante da grande valorização do capital e dos interesses pessoais, faz-se necessário um olhar mais íntimo para a cidade e para a preservação cuja trajetória poderá ser mantida durante todas as gerações. Demarcando as características locais, que ajudaram a formar o presente, tem valor relevante para a conservação e para a identidade da cultura de um povo. Tal esboço serve para validar que a arquitetura de uma cidade conta a história e contribuem para manter vivos os costumes, a identidade de uma sociedade e a memória nacional, além de provocar a valorização do lugar pelos moradores. No entanto, para 
conservar a memória de uma nação é preciso conservar a memória de cada estado e município, a começar pelo nosso.

\section{SÃO MIGUEL DO OESTE NO PRINCÍPIO}

A migração faz parte da história de diversos países, estados e municípios, sendo motivada por diversos acontecimentos, seja por pandemias, Guerras, fome, miséria, entre outros. No caso do Brasil, as migrações foram constantes durante um determinado período de sua história, onde grupos vinham de outros continentes em busca de trabalho e melhores condições de sobrevivência. (FAUSTO 1998). Da mesma forma, as migrações internas também foram relevantes e, em sua maior parte, foram ocasionadas pelos fatores econômicos. A exemplo, a colonização e povoamento do Extremo Oeste de Santa Catarina foi motivado, principalmente, pelo fator econômico. Em especial, pela expansão das fronteiras agrícolas, exploração de madeira para serragem, transporte e exportação, além da busca por terras férteis e baratas, já que as terras gaúchas haviam se esgotado, tornando-se impróprias para o plantio de cereais, o que levou inúmeras famílias de $\operatorname{colonos}^{6}$ a migrar para terras catarinenses em busca de solo fértil (DE BONA, 2004).

Segundo Staub (1960), no início retiravam da mata os recursos para a construção que abrigou os colonos e carpinteiros que trabalhavam nas primeiras obras do novo povoado. A partir do ano de 1940, aumenta o número de colonizadores que chegava à região, trazendo consigo um espírito mais empreendedor, sendo então fundada a empresa colonizadora Barth Benetti \& Cia Ltda. Nos primeiros meses foi delimitado o local para a sede do povoado que se iniciava e construído um barracão provisório para as famílias, assim como a instalação de um templo católico. Em 1944, chegou ao local o administrador Olímpio Dal Magro, que por sua visão e eficiência, conferiu à empresa o sucesso alcançado tanto na extração e exportação de madeiras, quanto na colonização (DE BONA, 2004).

Após o desmatamento, a primeira medida de Olímpio Dal Magro foi a elaboração de um projeto de loteamento. A área, em forma de triângulo, foi dividida em quadras e em 500 lotes urbanos. A área que rodeou o loteamento foi dividida em chácaras de 2,5

\footnotetext{
${ }^{6}$ Família de agricultores proveniente das colônias velhas do Rio Grande do Sul. 
hectares e o restante das glebas adquiridas teve sua divisão em blocos e estes subdivididos em lotes coloniais ou rurais, para serem vendidos aos colonos que chegavam (DE BONA, 2004).

Após a divisão, o administrador iniciou a abertura da avenida Getúlio Vargas, com largura de 25 metros, fixando em 20 metros a largura das demais ruas. No entanto, o projeto de dimensões das ruas e avenidas não agradou os diretores da empresa. Os mesmos exigiam que a largura fosse de 15 e 11 metros, respectivamente. Olímpio Dal Magro, com sua visão futurista e baseando-se no trânsito de Florianópolis (SC), permitida somente em uma direção, devido à pouca largura das ruas afirmou: "Daqui a 50 anos, quando isto aqui for cidade, nós não estaremos aqui para ouvir as críticas. Agora a terra é barata, mas no futuro vai valer muito e aí será tarde”. Diante disso, os diretores concordaram com as dimensões propostas pelo administrador, e assim, instituiu-se os modelos conhecidos das vias do município de São Miguel do Oeste (SC) (DE BONA, 2004).

De acordo com a Lei Complementar 003/2011 prevista no Plano Diretor do município de São Miguel do Oeste, as vias previstas para loteamentos industriais não devem possui largura inferior a 20 metros.

O traçado do município de São Miguel do Oeste (SC) inicia-se na Avenida Willy Barth, já que ela faz a ligação da entrada e saída da cidade com os municípios vizinhos por meio da BR-163. O traçado possui forma quadrangular e retilínea, com os lotes divididos em quadras de aproximadamente 100 metros de comprimento.

\section{A CONFIGURAÇÃO ATUAL}

No ano de 1958, apenas $15 \%$ da população de São Miguel do Oeste (SC) vivia na área urbana, no entanto, apesar do baixo número de habitantes, o munícipio continuava seu desenvolvimento, melhorando gradativamente seus equipamentos e infraestrutura. Em 1965 São Miguel do Oeste (SC) já contava com novas edificações, escolas, agências bancárias e moradores, sendo vista como uma cidade de evolução e progresso na região. Diante desse crescimento, os serviços mais urgentes a serem realizados eram o nivelamento e a abertura de novas ruas, o calçamento das ruas centrais, assim como a ampliação do perímetro urbano (SILVA, 2010). 
De acordo com Silva (2010), a configuração urbana do município nesse período mostrava-se funcionalista e ordenada. Contava com largas vias dispostas em um plano retilíneo, dividida em uma forma geométrica clara. Isso aconteceu pois São Miguel do Oeste (SC) foi projetada desde seu início, na década de 1940, seguindo o modelo de cidades modernas do mundo ocidental. Ela foi criada para ser organizada, bonita e progressista. No ano de 1970, quando entrou em vigor o novo Plano Diretor, a largura de 20 e 25 metros para ruas e avenidas foram mantidas, tendo sido definidas assim desde o início da colonização (SILVA, 2010).

A partir da década de 1950, a área urbana começa a crescer, principalmente nos arredores da Igreja Matriz São Miguel Arcanjo. Já na década de 1960, o município desenvolve-se no eixo norte-sul, acompanhando a Rua Waldemar Ramgrab, que naquele momento era uma das principais vias de acesso a São Miguel do Oeste. Na década de 1970 e nos anos seguintes, ocorreu um aumento do perímetro urbano, principalmente pela vinda de agricultores das áreas rurais, momento em que as ocupações começaram a acontecer de forma desordenada e irregular, aumentando o número de loteamentos feitos em chácaras, alterando definitivamente a fisionomia do município de São Miguel do Oeste (SC) (SILVA, 2010).

Nos dias atuais, o município já atingiu um maior grau de desenvolvimento, com diversos loteamentos novos nos arredores, novas ruas e caminhos a serem percorridos. No entanto, no decorrer deste tempo, a configuração das ruas foi se modificando. Por meio de pesquisa em campo, percebeu-se que as ruas em determinados loteamentos do município de São Miguel do Oeste (SC) não possuem largura conforme a lei. A medição foi realizada em 02 loteamentos em porções opostas da cidade, onde um apresentou rua com 8 metros de largura no total, sendo 2,5 metros destinados para cada caixa de rua e 1,5 metros de acostamento em cada lateral. No segundo loteamento analisado, a rua contava com 10 metros de largura, com 2,5 metros para as caixas de rua e 2,5 metros para cada acostamento lateral. A Lei Complementar 003/2011, Art. $9^{\circ}$, item IV, p. 3, prevista no Plano Diretor do município afirma referente às dimensões das Vias Locais: Local: 14,00 m (quatorze metros), sendo: a) 6,00m de caixa (2 faixas de circulação com 3,00m cada); b) 2,00m de acostamento para cada lado; c) 2,00m de passeio para cada lado. 
Foi percebido, de acordo com as visitas aos novos loteamentos, que, não somente as ruas diminuíram, mas também o tamanho dos terrenos, que no princípio eram grandes, com espaço para a residência e pátio, tanto na frente quanto nos fundos. Hoje, há lugar somente para a residência, com os recuos e área permeável necessária. Isso ocorreu também em função do capital, já que, diminuindo a área de cada terreno, poderia se ter um maior número deles a venda e consequentemente um maior lucro de mercado.

Além disso, é possível perceber a partir da análise de mapas da cidade, que além da largura necessária, as ruas e avenidas perderam seu formato e continuação, abstendose da forma quadrangular retilínea que caracteriza o centro da cidade. A medida que as ruas avançam para as periferias, perdem o traçado característico, assim como nos loteamentos, que mesmo sendo pensados e projetados, adotam medidas inferiores para as vias, com a intenção de aumentar o número de terrenos disponíveis para venda e consequentemente o lucro gerado por eles.

A medida que a cidade se desenvolve, valores primordiais, como a preservação do traçado urbano como patrimônio e história da cidade perdem-se, dando lugar a supremacia do capital e o poder. Portanto, não há mais a mesma preocupação que havia no princípio, onde os colonizadores pensavam no futuro e nas pessoas que aqui habitariam. Hoje, priorizam principalmente o lucro e o mercado imobiliário, esquecendo-se da parte mais importante e mais prejudicada: a cidade, sua memória e evolução.

\section{CONSIDERAÇÕES FINAIS}

O mundo da mercadoria se amplia gradativamente, onde tudo se compra e tudo se vende e o principal objetivo do capitalista é gerar dinheiro e obter lucro. A terra torna-se um objeto de comercialização e de grande especulação imobiliária, principalmente nas cidades, sendo fracionada e vendida em parcelas. Diante disso, a cidade moderna tornase refém do capital, passando a ser moldada pelo poder econômico.

Torna-se cada vez mais difícil programar e pensar o desenho e o traçado de uma cidade. Isso compromete não somente sua história, mas o desenvolvimento do seu traçado. Legado deixado pelos pioneiros fundadores dessas terras. A paisagem de uma 
cidade é composta pela relação do novo e do velho, no entanto, essas partes devem completar-se e terem uma continuidade, demostrando respeito e valorizando sua história que é a identidade do seu povo

Além da valorização, essa história contada por meio das edificações históricas e o traçado das cidades revelam quais eram os saberes que aquele povo possuía quando passaram a pensar e desenhar as primeiras ruas e estradas, quais eram os costumes, porque se construiu dessa maneira, quais eram os materiais que estavam disponíveis na época e quais eram os problemas a serem enfrentados na construção. Da mesma forma é possível fazer essa leitura na atualidade e observar como a sociedade molda o espaço. Portanto, preservar esses bens, seja eles moveis ou imóveis, de âmbito cultural, histórico ou ambiental, significa reconhecer seus valores e dar importância à identidade e a história de um povo.

A cidade enquanto concentração de pessoas, trabalhadores e reserva de mão de obra, produz e reproduz a divisão social do trabalho. A articulação entre trabalhadores e indústria implica, também, uma configuração espacial própria, capaz de permitir o consumo, distribuição e troca. Nesse caso, a infraestrutura como: ruas e rodovias ganham importância, uma vez que a circulação de mercadorias e pessoas é fundamental para que o capital se desenvolva. Assim, o traçado urbano de uma cidade perde seu caráter histórico para desempenhar papel articulador do processo produtivo trabalhocapital.

\section{REFERÊNCIAS BIBLIOGRÁFICAS}

BONA, Avelino de. Evolução Histórica de São Miguel do Oeste - SC: Edição Comemorativa do Cinquentenário da Instalação do Município (1954 - 2004). São Miguel do Oeste: McLee, 2004.

CARLOS, Ana Fani Alessandri. A Cidade. 6 ed. - São Paulo: Contexto, 2001.

. O espaço urbano: Novos escritos sobre a cidade. São Paulo, Contexto, 2004.

CHOAY, Françoise. A Alegoria do Patrimônio. $4^{\mathrm{a}}$ ed. - São Paulo: Estação Liberdade: UNESP, 2006.

FAUSTO, Boris. História do Brasil. $6^{a}$ ed. - Editora de Universidade de São Paulo: Fundação do Desenvolvimento da Educação, 1998. 
FUNARI, P. P., PELEGRINI, S. C. A. Patrimônio Histórico e Cultural. Rio de Janeiro: Jorge Zahar Ed., 2006.

IPHAN - Instituto do Patrimônio Histórico e Artístico Nacional. Disponível em: <http://portal.iphan.gov.br/>. Acesso em 22 Set. 2018.

LAMAS, José Ressano Garcia. Morfologia urbana e desenho da cidade. Lisboa: Fundação Calouste Gulbenkian, 2011.

LEFEBVRE, Henri, A Cidade do Capital. Tradução Maria Helena Rauta Ramos e Marilene Jamur. Rio de Janeiro: DP\&A, 1999.

Lei Complementar 003/2011 - Normas relativas ao sistema viário do Município de São Miguel do Oeste, Estado de Santa Catarina, e da outras providências. Disponível

em: $\langle$ https://www.saomiguel.sc.gov.br/plugins/ViewerJS/\#/uploads/5116.pdf $>$ Acesso em 15 Jan. 2019.

MASCARÓ, Juan Luis. YOSHINAGA, Mário. Infra-estrutura urbana. Porto Alegre: Masquatro, 2005.

SILVA, Adriano Larentes da. Fazendo cidade: memória e urbanização no extremo oeste catarinense - Chapecó, SC : Argos, 2010.

SOMEKH, Nádia - Organizadora. Preservando o Patrimônio Histórico: um manual para gestores municipais. (201-)

STAUB, Euclides, STAUB, José Raul, 1960. Povoamento e Colonização do extremooeste de Santa Catarina: segundo os primeiros moradores. São Miguel do Oeste: Gráfica Porto Novo/Editora e Gráfica São Miguel, 2014. 